\title{
The Impact of Brexit on the UK Economy
}

By Dimitrios Syrrakos ${ }^{1}$

\section{$\underline{\text { Introduction }}$}

The Brexit outcome of the UK's EU Referendum on June the $23^{\text {rd }}$ has led to heightened uncertainty in the UK economy, given the eventual structural changes it would entail and the considerable challenges to be faced in the process leading to its realisation. The structural changes will involve new trade relations and lower capital mobility with the remaining $27 \mathrm{EU}$ member states. The hurdles in the process emanate primarily from the negotiations with the EU-27 concerning the new relations that will govern trade. The swift restoration of a new UK government in the summer of 2016 saw that economic uncertainty has, so far, be decoupled by political turmoil. That is not to say of course, that political turbulence should be ruled out, in the way leading to Brexit. The Chapter consists of four parts. The first, evaluates the implications of the PM's Speech on the $17^{\text {th }}$ of January and the EU responses it prompted. The second assesses the current UK-EU macroeconomic framework and changes to it brought about by the Referendum and the impeding Brexit negotiations. The third part draws on Brexit's impact on SMEs from changes in the UK-EU27 trade relations. Finally, the fourth section focuses on the UK manufacturing sector and the strategies that could be adopted to mitigate the impact of Brexit, while seeking to take advantage of new opportunities.

\footnotetext{
${ }^{1}$ Dr Dimitrios Syrrakos BSc, MA, PhD

Principal Lecturer in Economics

Department of Accounting, Finance and Economics

Faculty of Business and Law

Manchester Metropolitan University

All Saint Campus, Oxford Road, Manchester

M15 6BG

Tel: +44 (0)161 2476484

Email: d.syrrakos@mmu.ac.uk
} 


\section{PMs Speech - Implications and EU Responses}

The Maastricht Treaty of 1992 identified the conditions that EU countries should observe once they have joined the EU's Single Market. These conditions are based on the principles of free movement of capital, goods, services and labour. By the second half of the 1990s, free movements of labour came to imply free movement of people.

Trade relations between the UK and the rest of the EU, while the former remains an EU member, represent the optimal trade relations the UK can secure with other countries, in this case other EU members. The PM's Speech on the 17th of January by ruling out continuation of Single Market membership implies that the outcome of the negotiations the UK government is about to embark with, with the rest of the EU cannot resemble the current trade relations. As a result, only a second or third best is attainable. In the words of Conservative MP and Chair of the Commons Education Committee Neil Carmichael:

"The Prime Minister's commitment to trading as freely as possible with the EU is welcome, but the best possible trading arrangement with the EU is full participation in the single market. No other arrangement is comparable, and so if the Government abandons membership of the single market, they will start the negotiations opting for second best." (The Independent)

The UK's macroeconomic arrangements and trade relations with other EU countries are depicted in Table-1 below. Exchange rate arrangements are presented horizontally at the top and trade relations are depicted vertically on the left. Brexit, with curbing immigration 
implications, as reinforced by the PM Speech will inevitably place the UK under different (less advanced) trade arrangements with all remaining EU-27 countries. This second best scenario, a variation of 'hard-Brexit', will see the UK's trade relations with the rest of the EU downgraded to retaining access to (a much needed) Customs Union.

Table-1

EU Trade Relations and Exchange Rate Arrangements

\begin{tabular}{|c|c|c|c|}
\hline \multicolumn{4}{|c|}{ EUROPEAN UNION MACROECONOMIC FRAMEWORK } \\
\hline & \multicolumn{3}{|c|}{ CURRENY - EXCHANGE RATE RELATIONS } \\
\hline \multirow[t]{2}{*}{ TRADE RELATIONS } & Flexible & Fixed & Common \\
\hline & Exch. Rates & Exchange Rates & Currency - Euro \\
\hline \multicolumn{4}{|l|}{ World Trade Organis. } \\
\hline & Cliff-Edge & & \\
\hline Free Trade Area & $\Delta$ & & \\
\hline Common Internal & Very Hard & & \\
\hline Tariffs and Quotas & Brexit & & \\
\hline & $\Delta$ & & \\
\hline \multicolumn{4}{|l|}{ Customs Union } \\
\hline Common Internal & Turkey? & & \\
\hline and External & Hard Brexit: & & \\
\hline Tariffs and Quotas & 4 & & \\
\hline Single Market & Soft Brexit - & Poland, & France, Germany \\
\hline Common Internal & accessing Sinlge & Denmark & Italy, Spain, Lux., \\
\hline and External Tarrifs & Market & Sweden & Austria, Ireland \\
\hline and Quotas & & Bulgaria & Belgium, Portugal \\
\hline PLUS & UK & Romania & Finland, Cyprus \\
\hline Coordination of & & Hungary & Holland, Greece \\
\hline Macroecon. Policies & & & Slovakia, Slovenia \\
\hline and/or reduction of & & & Lihtuania, Latvia, \\
\hline Exchange rate volatility & & & Estonia, Malta. \\
\hline
\end{tabular}

The PM's Speech despite demarcating the UK's negotiating framework, based on the 12 objectives provided, it did not explicitly clarify the type of trade relations it seeks to establish with the EU in the post-Brexit environment. For example, objectives 8 and 9 are inherently inconsistent. Objective-8, called for the UK seeking a 'Comprehensive Free Trade Agreement 
with the European Union'. At the same time though, the PM recognised that: 'But I want to be clear. What I am proposing cannot mean membership of the Single Market'. The PM then went on to say:

'That Agreement may take in elements of current Single Market arrangements in certain areas - on the export of cars and lorries for example, or the freedom to provide financial services across national borders - as it makes no sense to start again from scratch when Britain and the remaining Member States have adhered to the same rules for so many years. So an important part of the new strategic partnership we seek with the EU will be the pursuit of the greatest possible access to the Single Market, on a fully reciprocal basis, through a comprehensive Free Trade Agreement. ' [Italics provided].

The UK government's stance causes confusion and often dismay to EU officials. If an EU country acknowledges that curbing immigration implies no Single market membership, then that country cannot have access to the specific Single Market's elements in certain areas of interest. Preferential access (access a la carte) cannot be granted. This is the case, not because the EU wants to punish the UK, but because it would undermine that functioning of the Single Market itself. If the UK is able to export cars to EU's Single Market (e.g. to France and Germany), without paying its contributions to EU, why should not other EU countries have the same deal, while losing market share to the UK automobile industry? As a consequence, there cannot be the greatest possible access, (or any access) to the Single Market. Effectively this means that the nature of Brexit is going to be hard. 
However, regardless of the clarity provided concerning the UK's negotiating stance, in terms of not seeking continuation of Single Market membership, further confusion was caused in relation to Customs Union Membership. In setting objective-9 on new trade agreements with other countries, the PM acknowledged:

'I know my emphasis on striking trade agreements with countries outside Europe has led to questions about whether Britain seeks to remain a member of the EU's Customs Union. And it is true that full Customs Union membership prevents us from negotiating our own comprehensive trade deals. [...] Whether that means we must reach a completely new customs agreement, become an associate member of the Customs Union in some way, or remain a signatory to some elements of it, I hold no preconceived position. I have an open mind on how we do it. It is not the means that matter, but the ends.'

As full membership of a Customs Union precludes establishing free trade areas independently with third parties, it can only be concluded that the UK is contemplating leaving the EU'S Customs Union. To understand why this is the case consider the following scenario, which is highly likely to emerge if objectives 8 and 9 as set out by the PM were implemented. Assume the UK, following Brexit, is granted full access to the EU's Customs Union, and at the same time exceptionally permitted to join trade agreements with other countries. Soon after, the UK and the USA could create their own Customs Union. This implies that the UK would be party to two separate Customs Unions, and as a result, imported products from the USA could flood the EU Customs Union via the UK. 
This would clearly undermine the functioning of the EU's Customs Union and would not be viable. Eventually, the UK would either be requested to apply the EU's external tariff and nontariff trade barriers to USA goods and services (effectively dissolving its Customs Union with the USA), or leave the EU's Customs Union. This example, illustrates why not a single country is party to two Customs Unions. Going back to the example, the only way for this to be the case, is for all other EU countries to accept the terms and conditions of the USA-UK Customs Union. This would then imply that the two customs unions have merged to one Customs Union including the EU-UK-USA.

This rules out the PM's proposal for a new customs agreement, as any agreement would have to be inferior to the EU's Customs Union. However, it does not rule out, limited or preferential access. Assuming good will from the part of the EU, limited access to the EU's Customs Union could form the basis for an agreement. And this is exactly what the PM offered and clarified on her Speech. The crucial issue therefore, the negotiations would focus on is what markets such an agreement would include. Ultimately, compromises would have to be made from the UK' negotiating team, in particular concerning financial services. To conclude, the PM's speech provided clarity by recognising that soft Brexit is no longer an option (ruling out the small arrow on the left hand side in table-1, and moving to somewhere between the two middle arrows). This would point to an agreement that falls short of full access to EU's Customs Union but it is much superior to a free trade area. This is relatively encouraging as it conveys the message to the EU that the UK is ready to negotiate on the grounds of an inferior variant of the EU's Customs Union agreement. By doing so, the PM Speech shifted the debate away from 'soft vs hard' Brexit, to one over 'hard vs very hard' Brexit, while pointing its preference for a consensus closer to the former. 
Notwithstanding the difficulties in making a prediction for the final agreement the framework set by the PM indicates that it could resemble in some ways the EU-Turkey customs union subject to differences in the sectors it would include.

It needs to be noted though, that the Common Market guidelines regulate only around $40 \%$ of the EU member countries economic activity with areas such as financial services and insurance largely not included. Hence, the UK's government proposals for, in effect a 'sectorby-sector' access to the Single Market. Such an approach would make sense, provided the European Commission (EC) allows individual EU countries to negotiate bilateral trade agreements with the UK on specific sectors, such as insurance. However, given that the EC's objective is to enlarge the Single Market competency areas and to include as many industries as possible, this is highly unlikely (Morales, 2017). As Chancellor Merkel pointed out in response to the PM's Speech: 'The main thing is that Europe does not let itself be divided and we will make sure of that via very intensive dialogue'. A consensus similar to the SwitzerlandEU's trade agreement should not be ruled out, ensuring access to specific Single Market areas. This of course would involve a compromise from the UK government as it would limit its ability to reduce immigration from the EU and it would also have to continue making contributions to the EU.

Failure to secure access to the Single Market and the Customs Union will lead the UK's trade relations with the rest of the EU to a free trade area, or a 'very hard' Brexit. Failure to agree even on a free trade area between the UK and the EU's free trade area, will relegate the UK's trade relations to World Trade Organisation (WTO) regulations that broadly allow free trade but subject to countries' unilateral tariffs and quotas. 
Much desired flexibility from the rest of the EU countries and the European Commission could facilitate an agreement, based on a version of the EU's Customs Union, permitting some curbing in immigration. However, as a Customs Union implies the adoption of common external tariffs and quotas it would be impossible to forge trade relations with other parts of the world, such as the USA, China, India and Australia.

Early signs from European Union officials are not encouraging. Guy Verhofstadt, the EU Parliament's representative in the negotiations (and former Belgian PM), summed up the PM's 12 objectives the day after the PM delivered her Speech, as 'creating an illusion that you can go out of the single market and the customs union and you can cherry pick and still have a number of advantages [ ... ]. He went on to add 'I think this will not happen. We shall never accept a situation in which it is better to be outside the single market than be a member of the European Union' (Khan, 2017). While visiting Washington, on the $26^{\text {th }}$ of January, Mr Verhofstadt also stated that 'The UK PM announced a very radical Brexit because she knows that the EU will never accept a situation in which the status of a country outside the union is more favourable than to be a member of the European Union' (Wishart, 2017). On the prospects of a new trade deal between the UK and the EU-27 to be delivered by 2019, pledged by the PM, Mr. Verhofstadt called it 'impossible'.

Sir Andrew Cahn, former Single Market advisor to the UK government and one of the architects of the EU's Single Market foresees a 'bitter' divorce. He also points out that 'The EU side, after all, in a way, have already won the first round of this negotiation because they have forced the UK to say 'no, we won't be in the single market' (Merrick, 2017). 
The volumes of trade involved are vital. The UK exported to the EU approximately $f 230 \mathrm{bn}$ in 2015 , which is equal to $47 \%$ of the $f 490$ bn of total UK exports (CBI, 2016). The rest of the EU exported $f 290$ billion to the UK (thus leaving a UK deficit to the rest of the EU by $f 60 \mathrm{bn}$ ).

Let's us assume that Brexit negotiations and a final 'hard Brexit' agreement lead to a $20 \%$ reduction in the intra EU-UK volumes of trade. A $20 \%$ reduction in the UK exports to EU, will lead to a decrease by $£ 46$ bn from $£ 230$ to $£ 184$ bn. However, more importantly it would also reduce total UK exports from $£ 490$ bn to $(490-46)=f 444$ bn, or $9.4 \%$ of total UK exports. On the other hand, a $20 \%$ reduction in the EU exports to the UK will see them reduced by $f 58 \mathrm{bn}$ to from $\mathrm{f} 290 \mathrm{bn}$ to $\mathrm{f} 232 \mathrm{bn}$. This would also reduce total EU exports from $\mathrm{f} 1.812$ th to f1.754 th, or $3.2 \%$ of total EU exports.

As a result, while hard-Brexit will prove detrimental for both the UK and the EU, it would approximately be three time costlier for the UK in terms of net exports. The same result is derived when comparing the intra EU-UK volumes of exports relative to their respective GDP. UK exports to EU equal $12 \%$ of the UK's GDP, whereas EU exports to the UK equals $3.5 \%$ of the EU's GDP (excluding the UK). Reflecting on the same issue, Ulrich Hoppe, the head of the German-British Chamber of Industry and Commerce, claimed that:

'Germany's trade surplus with the U.K. amounts to about 1 percent of the gross domestic product of Europe's biggest economy, and if 1 percent of German GDP grows slightly less or slightly more, it doesn't really matter to the German economy. So the idea that Germany from a business point of view will be very flexible towards the U.K. in the Brexit negotiations is a dream.' (Italics provided). 
The other side of this argument of course, is that the loss in net exports to the EU, will be more than compensated by the devaluation of the Pound, which will boost the export orders and thus the quantity of exports. Thus, while profit margins may be reduced per unit of exports due to potential tariffs, increased sales could generate more profits on aggregate. This maybe the case for as long as the UK remains in the Single Market. Post-Brexit it would depend on the nature of the tariffs and the extent of the pound's depreciation, the combined impact of which is almost impossible to anticipate. The exchange rate dimension to the argument is addressed in the following section.

\section{The UK - EU Macroeconomic Framework}

\section{Exchange rate arrangements}

The European Commission (EC) perceives exchange rate volatility as a barrier to trade. Its elimination is therefore conducive to the completion of the Single Market. Countries in the Eurozone (EZ) for example have chosen the most advanced type of a fixed exchange rate regime that of a currency union and have thus contributed to this aim. The UK on the other hand, while accepts the need for exchange rate stability, in this case in the Pound-to-Euro exchange rate it has maintain its monetary independence. This means that the Bank of England (BE) has retained the right to set the 'base rate' and target the Money Supply (MS) in line with the needs of the UK economy. This right was exercised soon after the Great Recession hit the UK economy. From spring 2009 -when the BE was convinced of the severity of the recession- to autumn 2012, the BE pursued unconventional monetary policies involving lowering the rate of interest to unprecedented levels, and adopting a Quantitative Easing (QE) 
programme that led to the injection of extra $f 375$ bn pounds in the UK financial institutions in four rounds.

This helped UK financial institutions to increase their capital and reserve requirements, however, it did not lead to increases in lending in the short run. As confidence to the UK was shattered, following the deficit's increase to $10.5 \%$ in $2009-10$, the new coalition government adopted a fiscal consolidation programme to accompany BE's expansionary monetary policy. The initial objective was deficit elimination by 2015 , when the next national election was due to take place. The policy framework of contractionary fiscal and expansionary monetary policy was considered the most appropriate by the UK coalition government.

However, the private sector's response to expansionary monetary policy was not the one anticipated. Banks and private sector companies hoarded money, instead of investing, given the prospects of another recession in 2012. Eventually, as the deficit was gradually reduced, albeit not to the extent initially projected, confidence was gradually restored leading the UK economy becoming the fastest growing among the G7 during 2014-15. External developments, such as the Eurozone's debt crisis peak in 2011-12, saw the UK's safe haven status been restored. However, it has to be noted, that the positive developments in the UK economy, were taking place, in the background of unconventional monetary policy and productivity not recovering its 2008 rates. As in the long-run, it is productivity rates that determine whether countries become wealthier or poorer, a lot more work was/is required to take place in terms of infrastructure investment, education, R\&D etc. (Cadman, 2016). Overall though, the QE programme's effectiveness and the pound's depreciation in 2008 reaching 30\% against the USA dollar and the Euro, are evaluated as having a relatively positive effect on the UK economy at a time of considerable hardship. Gradually, after seven long 
years, towards the end of 2014 and 2015 the focus shifted away from unconventional policies, to forming expectations of when the BE will start raising the base rate towards more 'normal' rates. Overall, according to BE's estimations the QE programme, added 1 percent growth annually between 2010 and 2015 .

However, the BES QE programme, while helpful to the UK economy, had wider implications in the EU context. It placed the UK in a unique position. In order to understand why this is the case, we need to resort to exchange rate definitions.

At a basic level the exchange rate is the rate at which a currency e.g. the domestic currency (f) translates-converts to another currency (e.g. $f 1=1.15$ Euros). This is the bilateral exchange rate, that is the units of another currency that 1 Pound can buy. Another definition is based on the real effective exchange rate. This is based on a weighted average of the exchange rates of the most important trading partners of the country under perspective. As a result, the real effective exchange rate provides an objective way of judging the relative strength of the domestic currency against a basket of other currencies. For example, by focusing only on a particular bilateral exchange rate, e.g. the Pound to South African Rand, it is very difficult to assess the overall impact of the Brexit vote on the Pound's performance. This is particularly the case, when contrasting trends are observed in bilateral exchange rates. For example, the value of the pound has declined significantly in relation to the Euro since June but has remained relative stable in relation to the Russian Ruble. Thus, it becomes very difficult to pass judgements on the overall performance of a currency by drawing on specific bilateral exchange rates. The real effective exchange rate resolves this problem, but focusing on the trends of the bilateral rates of the currencies of the 24 (or 26) most important trading partners. In this way, the effects of an 'outlier' bilateral exchange rate trend are minimized. 
The real effective exchange rate raises the question over the definition of the real exchange rate. The Real Exchange Rate (RER) equals the bilateral-(nominal) exchange rate multiplied by the ratio of the price of exports over the price of imports.

$$
\text { Real ER }=\text { Nominal ER } \times \frac{P_{\text {Exports }}}{P_{\operatorname{Im} \text { ports }}}
$$

In a fixed exchange rate regime, the bilateral-nominal exchange rate is irrevocably fixed and any adjustment to economic shocks has to come by the price ratio of exports over imports. Fixed Exchange Rates

$$
\text { Real ER }=\text { Nominal ER } \times \frac{P_{\text {Exports }}}{P_{\text {Im ports }}}
$$

This reflects the need for the domestic economy to become competitive in the short run, by reducing the cost of production in the productive sectors of the economy, such as export industries. This reduces export prices, and as such, the export-to-import price ratio will decline, causing an overall reduction in the RER. This mechanism provides the main theoretical rationale in favour of fiscal cuts in Southern Eurozone. Overall, the nominal exchange rate (which is fixed and cannot be adjusted) will be multiplied by a lower export-to -import price ratio and it will lead to a depreciation in the RER, stimulating further the volume of exports.

\section{Fixed Exchange Rates adjustment via}

Real ER $=$ Nominal ER $\times \frac{P_{\text {Exports }}}{P_{\operatorname{Im} \text { ports }}}$

\section{Flexible Exchange Rates adjustment via}

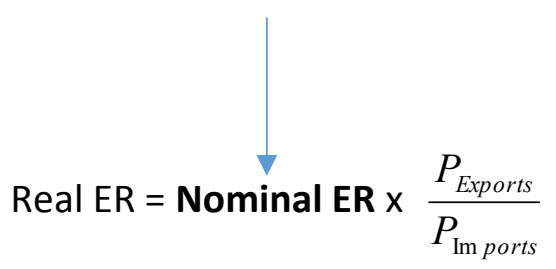

On the other hand, under flexible exchange rates, the adjustment to economic shocks in the short run, is delivered from the depreciation in the nominal exchange rate, without requiring an immediate adjustment to the exports-to-imports price ratio. The depreciation 
(or devaluation), reduces the nominal exchange rate thus causing a decline to nominal ER $\mathrm{x}$ export-to-import prices. Overall, the RER declines, facilitating the restoration in competitiveness caused by the shock. As a result, the adjustment of the UK economy to the Brexit outcome of the EU Referendum in June is facilitated by the significant depreciation in the nominal exchange rate of the Pound. This has already boosted orders for domestically produced goods and services from the rest of the EU and the US in particular. This is particularly the case for the UK manufacturing sector.

The above analysis does not imply that the exports-to-imports price ratio would not adjust in the medium-to-long run even under flexible exchange rates. The crucial issue is that this adjustment does not need to take place immediately, so that flexible exchange rates provide more time to the domestic economy to adjust to the newly emerged environment. This provides one of the main advantages of flexible exchange rates.

The above discussion on the adjustment mechanisms under fixed and flexible exchange rates respectively, leads to the question of what drives the (nominal) price of a currency to decline. In order to account for this, the determinants of the exchange rate need to be presented. The main determinants of the value of the domestic currency include:

i) the volumes and composition of trade (Balance of Payments);

ii) the rate of interest in relation to the rates of interest in other major economies;

iii) the domestic price level;

iv) growth performance;

v) economic fundamentals.

Increased volumes and favourable terms of trade, that is exports exceeding imports, will lead to surpluses in the UK's balance of payments placing upward pressure on the value of the pound. On the other hand, persistent decreases in the volume of exports accompanied by increases in imports, would lead to deficits in the UK's balance of payments putting downward 
pressure on the value of the Pound. The rate of interest is the main short-term determinant of the value of the domestic currency. An increase in the BE's interest rate (base discount rate) would lead to an increase in the value of the pound, in the absence of interest rate changes abroad. Likewise, a decrease in the base rate, would lead to a depreciation. Higher inflation than abroad leads to a depreciation in the value of the Pound in the long-run. In the short-run however, it can prompt an appreciation if it leads domestic residents to expect an increase in the base rate, to counter inflationary pressures.

Lastly, a deterioration in the domestic economy's fundamentals would lead to a depreciation. Economic fundamentals, include industrial production, cost of production per unit of output, technological innovation and adaptation to production among others.

The determinants of the exchange rate should not be viewed in isolation. Assume for example, that there is persistently higher inflation in the UK than in France. This imply that year-on-year producing the same product in the UK would gradually become more expensive than producing it in France. As a result, sales of the product made in France will increase in international markets, at the expense of the sales of the UK product. This would have a negative impact on the volumes of UK exports, and therefore on the terms of trade, in particular the current account of the balance of payments. It would also have a negative impact on the UK growth potential. This would cause the value of the pound to depreciate. Likewise, when the Bank of England supplies more pounds to the economy, the Pound's value would decrease, causing a reduction in the cost of production in the UK in international terms, in the short run. In the medium to the long run, import push inflation will pass through the production process and the UK's competitive advantages emanating from the devaluation would be reduced if not eliminated (Meakin, 2017). There are the kind of inflationary processes the UK economy is currently experiencing (ONS, 2017). 
To summarize, the supply of money therefore presumes a free-floating exchange rate and independent monetary authorities. Countries, that chose to join a fixed exchange rate regime and replace their currencies with a common currency (e.g. France, Germany, Italy etc.), surrender monetary independence in the sense that they cannot increase the money supply for domestic policy objectives. Reducing exchange rate volatility, which can be facilitated by joining a fixed exchange rate regime with another country's currency, would be conducive to enhancing the volumes of trade between the two countries in the regime (e.g. France and Germany).

The only EU country that has retained full monetary independence is the UK. The UK economy as a result functions within a macroeconomic framework featuring, free movements of capital, labour movements, free trade (including free movements of goods and services) and flexible exchange rates. The Eurozone member countries' economies on the other hand, are in an environment of irrevocably fixed exchange rates (EZ), free capital and labour movements and free trade. These arrangements place the BE in a unique position within the EU framework. It has the right to engage in expansionary monetary policy without consent of other EU countries to mitigate the negative impact of recessions, like the Great Recession during 2008-09 and the Brexit shock in 2016. The schematics of the UK positioning in the EU context is presented below. As it can be observed the UK's current arrangements in the EU lead to Pound-to-Euro exchange rate volatility. 


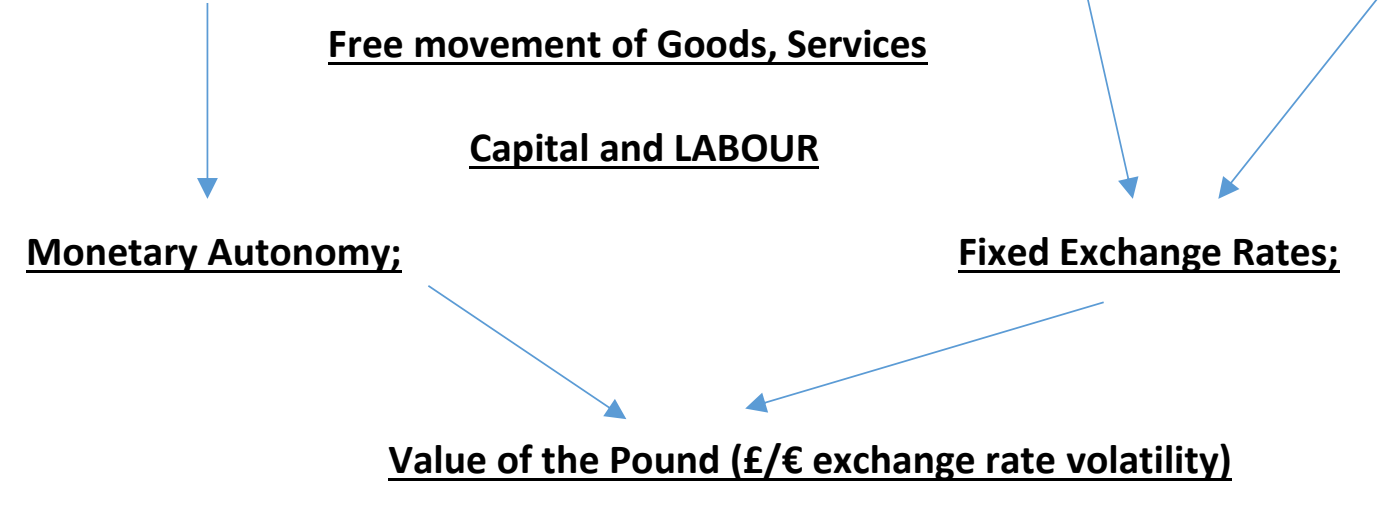

Such volatility has been observed since 2008. During 2014-15 the Pound appreciated considerably, leading to a Pound-to-Euro exchange rate of 1.42 and to a Pound-to-Dollar exchange rate of 1.45 in December 2015. The significant appreciation in the value of the Pound during this period, reflected the gradual restoration of confidence in the UK economy, prompted partly by the halving of the 2010 deficit, and partly due to the growth performance of the UK economy, which as mentioned registered the highest growth among G7. On the other hand, this favourable macroeconomic environment took place on the background of low productivity and unbalanced growth, both in terms of its drivers and regional performance (Smith, 2017). Growth was driven primarily by services and less so by construction and exports and was heavily focused on the South with many regions around the country, not recovering their 2008 output loses.

This trend has persisted well into 2016, as the latest preliminary growth figures for Q4 2016, while confirming the UK's strong growth momentum (0.6\% in Qs 2-3-4 and 2\% for 2016) also reflect its unbalanced nature, as its major driver was services (ONS, 2017b). Other major international organisations have also confirmed this trend and their short-term forecasts point to a slowdown in growth while Brexit negotiations are under way. The International 
Monetary Fund projects a growth of $1.1 \%$ for 2017 , a rate echoed by the World Bank that expects growth of $1.2 \%$ for the current year, and $1.3 \%$ in 2018. The Bank of England, slightly more optimistic anticipates growth to slow to $1.4 \%$ in 2017 and $1.5 \%$ in 2018 . The Office for Budget Responsibility, forecasted a growth rate of $1.4 \%$ for 2017 and $1.7 \%$ for 2018 .There is consensus for the reasons for the slowdown in growth including Brexit negotiations, and its unbalanced nature (Cox-2017b).

\section{BE's 2\% inflation target - The Pound}

The Bank of England adhere to the principle of flexible inflation targeting. While inflation in the UK has been maintained below the $2 \%$ inflation target since 2013 , the Pound's drop since July 2016 has caused import prices to increase in $f$ terms. As import-push inflation passes through into the UK production process, via e.g. higher food prices, eventually this will lead/has led to higher inflation in the UK. The BE in its August report, produced a forecast for a rate of inflation of $2.7 \%$ in 2017. BE Governor Mark Carney and the Bank's Monetary Policy Committee have already communicated that they will not increase the base rate, in the case of a one-off violation of the $2 \%$ inflation target provided it is maintained at reasonable levels. However, the forecast assumed no further depreciation in the value of the pound. Major financial institutions such as HSBC and Deutsche Bank, Germany's Central Bank, expect the pound to further, depreciate another 5 and $10 \%$ respectively, reaching a low of $\$ 1.10$. This was attributed first to political uncertainty and second to the UK's wide external imbalances that persists, at least so far, despite the devaluation that took place in the aftermath of the Referendum (Spezzati, 2017). 
Overall, in the medium to long run the Pound's depreciation will lead to a re-allocation of resources from SME's (and sectors of the economy) that are exposed to the increase in import-push inflation to SMEs (and sectors of the economy) that are not. Assume an SME firm, SME-A, is less exposed to import-push inflation and not dependent on the influx of less skilled labour from EU countries. It would, eventually, be in a competitive advantage in relation to another SME, SME-B that is exposed to import-push inflation and is dependent on less skilled labour from East EU countries. If SME-A's main export market is the USA, whereas SME-B's main export market is France or Germany the competitive advantage would widen even further. It could also be the case that SME-A is not an export-orientated company but entirely dependent on developments in the UK economy (e.g. a construction firm). The extent of the resource re-allocation away from SME-B to SME-A would be dependent on the final Brexit agreement.

Following the Brexit outcome delivered in the EU Referendum the Pound dropped significantly in particular in relation to the US dollar and the Euro. The decline has been more significant against the dollar to levels not seen since the mid-1980s. In relation to the Euro, the pound has dropped back to its 2011 level. To date the depreciation has reached $20 \%$ in against the dollar and 13\% against the Euro from its January 2016 value.

\section{Pound-to-Dollar}

One of the interesting features of the exchange rate volatility in the value of the Pound, postReferendum has been its dramatic decline in relation to the USA dollar. What has prompted this decline? There are three main reasons. 
First, it is the outcome of the Referendum, which caused/s uncertainty in foreign exchange markets leading to a decline in most of the Pound's bilateral exchange rates, and as a result, a decline in the Pound's Real Exchange Rate. However, this reason alone cannot account for the magnitude of decline in relation to the \$US. A second reason, relates to the UK's record current account deficit in in 2015 that reached an overall 5.2\% (Albanese, et al. 2017). From a purely economic perspective, this reflects that the appreciation of the Pound during 2014 and 2015 was not sustainable. Even this, though does not suffice to fully explain the Pound's depreciation against the dollar, in excess of its decline against other currencies.

Why for example the Pound has receded to its 2011-12 value against the Euro whereas has dropped to levels not seen since the 1980s against the dollar? At this point, emphasis needs to be placed on events in the USA. The growth potential in the US economy has gathered enough pace to prompt the Fed to increase rates for the first time in 2016 . While there are still underlying problems in the USA economy, (e.g. labour market participation rate in the USA is $63-64 \%$ against the UK's rate of $74.5 \%)$, developments point to monetary policy divergence between the USA and the UK. The August decision by the BE to reduce the base rate to $0.25 \%$ conveyed a signal to markets that the adjustment of the UK economy to Brexit environment would take priority for the BE over short term considerations with the rate of inflation. The Governor of the BE has also acknowledged that a one-off inflation overshooting above the $2 \%$ target will be tolerated by the Bank in the short to the medium run, in particular as Brexit negotiations are taking place.

Assuming therefore that BE's inflation forecast for a $2.7 \%$ inflation in 2017 proves correct this will strengthen market's perception of a monetary policy divergence between the UK and the USA in the short to the medium run. This prognosis is of course in line with the Chancellor's 
extension of deficit elimination period, which has been pushed beyond 2020 , as emphasis is placed on the adjustment of the economy to the Brexit challenges.

Lastly, as 'Trumpenomics' raises the prospect for an even stronger USA growth performance, this reinforces market's expectations pointing to further interest rate hikes in the USA during 2017 and 2018. Thus, divergence in the USA and UK monetary policy, could lead to higher interest rate differential between the two countries, could precipitate capital inflows to the USA. This, combined with the above two reasons explains the sharp depreciation of the Pound in relation to the USA dollar.

As mentioned above, the forecast for a $2.7 \%$ inflation in the UK is based on the assumption that the value of the Pound will be maintained at its current levels. Given the markets' focus on the politics of Brexit, a further depreciation in the value of the pound cannot be ruled out (Albanese, 2017). The Pound-to-Dollar exchange rate will be crucial to companies exporting to the USA, as it would (has) boosted orders for UK goods and services. Given that the UK is about to embark on a process that will see it departing from the EU, relations in broad terms, but also trade relations in particular with the USA will be vital. This is the case, as the USA will provide an obvious candidate country that the UK should seek to enhance its trade ties with. A prospect, which already seems to be reciprocal from the new USA administration (Editorial, 2017). There are obvious obstacles that could hinder this process, such as the obvious delays in reaching a new trade agreement. However, given the political willingness in the USA, increases in the UK-USA volumes of trade should be targeted (Ross-Thomas, 2017). 


\section{Small and Medium Enterprises}

In terms of timely and adequate preparations for a smooth adjustment to a Brexit environment SMEs must assess, if not already identified, their exposure to Brexit negotiations. SMEs focusing primarily on domestic markets, such as construction companies, are by definition not dependent on sales to EU markets, are very well placed to adjust to the Brexit environment. The long-run threat to SMEs in this category, relates to the deterioration on the purchasing power of the UK households and increases in the price of oil. The higher the inflationary overshooting from the BE's $2 \%$ inflation target and the longer its duration beyond 2017, the more the purchasing power is going to be reduced (Ward, 2017a, 2017b). In this case, in the long-run SMEs in this category will suffer from the decline in households' real wages, which would sooner or, later translate to less spending. In the short-to-medium run, spending may be sustained as households' are prepared to take on more credit, or withdraw from savings to maintain their current standards of living. However, as credit accelerates, credit constraints will manifest themselves leading to less spending. Given the discussion above concerning the depreciation in the pound, SMEs in this category, should also develop contingency plans for rates of inflation reaching or exceeding the $5 \%$ threshold. Indeed, the substantial drop in retail sales in December 2016, at the fastest pace since 2012, enhances the legitimacy of the argument (Goodman, 2017).

SMEs that are not dependent on exporting to EU could still experience difficulties emanating from labour shortages, in particular of less skilled labour. This, apart from driving higher labour costs, as firms would compete for labour from a relatively fixed labour market could also hurt overall production. In this case, access to EU labour market could be rendered possible, depending on the final Brexit agreement, and assuming that the brunt of the cost of 
a job permits scheme, would be met by the UK government. This is an area that would require lobbying from SMEs. In the long-run, due to the potentially higher costs of accessing funds and financial services SMEs need to put aside funds to support these services once Brexit materialises. This is particularly the case, if there is no interim agreement in place following the two years' negotiation period, as stipulated by Article-50.

SMEs that have trade links with the USA should seek the UK government's assistance in terms of further enhancing them. From their part, such SMEs should seize this unique opportunity and start develop immediate plans, detailing steps that would facilitate such an enhancement. SMEs with limited access to USA markets or that do not have ties with USA should identify whether these are possible to establish. In this case, they should prepare draft feasibility strategies on whether trade ties with the USA can be developed. In case these strategies have the potential to be fruitful, they should seek grants (research grants, transport costs coverage, etc.) from the UK (and perhaps the USA) government as they seek USA markets. This can be the case in particular for SMEs that have strong existing ties with EU countries and as a result of Brexit, aim to diversify their markets. Minimising losses in the Single Market, subject to Brexit negotiations, and maximising sales to the USA is the obvious long run objective.

SMEs depending on the Single Market will be affected more severely. In the short-run though (2017-19), they should take advantage of the Pound's drop and maximise sales (and profits) before import push inflation erodes their price advantage from other competitors located in other EU countries, and in particular in the Eurozone, and before the current trade arrangements seize to exist. In this perspective, it is in the interest of these SMEs, if some access to the Customs Union is maintained. As, following the PM's Speech full access to the 
Single Market is highly improbable, access to EU's Customs Union could provide a viable way forward for a large number of SMEs that would face obstacles while trying to reach EU markets, but could mitigate these by the competitive advantage provided by the pound's drop. As a result, joining the existing EU's Customs union arrangements after 2019, in the absence of a Brexit agreement is vital. A (hard) Brexit agreement could provide access to UK goods and services in the EU Customs Union. However, contingency plans for a very hard Brexit should be in place, by the end of 2019 at the latest. These, should include plans for mitigating accelerating inflation to levels of $4.5-5.5 \%$.

Finally, in this context, it becomes vital for all SMEs to avoid a 'cliff-edge', where following an unsuccessful two-year period of negotiations access to Single market is lost, and there are no trade agreements with other countries (USA, India and EU). It is of paramount importance therefore all SMEs lobby the UK government and its negotiating team in particular for such a catastrophic scenario to be prevented. Contingency plans for a 'cliff-edge' should be prepared as early as possible, but they should not be viewed as the central scenario, for the present. They would amount to WTO rules and regulations for the UK exports for the EU markets and non-EU markets. 


\section{Table-2: Summary of SMEs Response}

\section{Small and Medium Enterprises}

Not exposed to EU markets

Exporting to EU Short-run: Maximise benefits from the Pound's decline -

Minimising cost from import-push inflation/oil dependency

Medium-run: Identify problems-break down in supply lines

Long-run: Contingency plans for higher cost of financial services and

Outcome depending on final Brexit agreement:

1. Soft Brexit: Access to customs union maintained - modest EU market losses that could be mitigated by the Pound's decline.

2. Hard Brexit: A free trade area with EU is put in place. Considerably losses in EU markets - further declines in the Pound likely Contingency plans for inflation ranging $4.5-5.5 \%$

3. Very Hard Brexit: WTO rules are put in place with EU. Considerable losses in EU markets from tariffs and non-tariff trade barriers - further declines in the Pound most likely - SMEs to hedge against foreign exchange exposure - Possible ties with the USA need to be identified

Contingency plans for inflation ranging 4.5 - 5.5\%/Balance of Payments crisis Lobby to avoid 'cliff-edge'

\section{UK Debt - SMEs}

The UK is borrowing money at historically low interest rates since 2011 . This could change quite considerably post Brexit and in particular in the foreign holders of UK debt view the Pound's decline as a permanent in nature, as a consequence of Brexit. As roughly around $27 \%$ of the UK's 1.6 trillion debt (approximately $84 \%$ of the UK's GDP) is owed by non-UK residents (approximately $430 \mathrm{fbn}$ ), a similar ratio by the BE and the rest by UK residents or UK based firms, pensions funds etc., the effects of non-UK residents selling UK debt could be significant. Indeed, the increase in inflation, has already caused a decline in bond prices and increased 
the yield of UK debt (Burton, and Mogi, 2016). At modest rates of inflation, this should not be a problem.

Uncertainty over Brexit negotiations could prompt a continuation on this trend, so that the yield could increase further from the current $1.35 \%$. While, this is not likely, in particular, if non-UK resident holders of UK debt view the pound' drop as temporary, it should be bore in mind by SME's. Given the complexities in the Brexit process, and unless market's expect an upward trend in the value of the pound in the next 3-5 years, an event which is highly unlikely, a declining ratio of foreign-to-domestic holders could cause an increase in the cost of borrowing and reduced access to funds. In addition, in this case, the cost of borrowing to firms and mortgages could increase substantially, with an adverse impact on economic growth. This is not a likely scenario, but one that SMEs need to be aware of. Therefore, SMEs need to identify whether a (permanent) depreciation in the value of the Pound to current (or even lower levels in the short-to-medium run) and the potential increase in the cost of borrowing could be mitigated by the increase in the orders and the volumes of exports that accompany such a depreciation (Syed, 2017).

Whether, the pound's depreciation would cause a deterioration in its reserve currency status, something that could lead to even higher cost of borrowing remains to be seen (Chu, 2017). With the USA dollar (63\%) and the Euro (20\%) accounting for $83 \%$ of reserve currency use, the Pound (4.5\%), and the Japanese Yen (4.5\%) as minor reserve currencies count for another 9\%. The remaining $8 \%$ is accounted by the Canadian and Australian dollars, the Swiss franc and other currencies. The $4.5 \%$ allocation to the Pound corresponds to approximately $f 280 \mathrm{bn}$ of reserves held in Pound Sterling (IMF, 2017). 


\section{The case for UK Manufacturing - a Positive Brexit Impact?}

Manufacturing in the UK has long been in decline both in absolute and relative terms. A variety of factors including de-industrialisation in the 1960s, 70 s and 80 s, international pricing competition from South Asia and East Europe since the early 1990s, automation processes-IT innovations and their application in the production process, globalisation and a truly international supply chain are among the most important. Membership of the EU since 1973, has also contributed by preventing the adoption of a 'national' industrial policy that could have favoured UK manufacturing. Competing in pricing was thus very difficult even in the 1970s. This acted against UK manufacturing due to the high cost of production, in relation to France and Germany. Later on in the 1980s, the UK government placed more emphasis on financial services, as they were viewed more promising in the long-run.

This led to a declining role for the manufacturing sector, which also suited the political objectives of the Thatcher conservative governments, aiming to reduce trade unions powers. Manufacturing featured the strongest trade union activity. Many firms that survived the 1970s and 80s, found it extremely hard to do so in the 1990s due to the downturn in 1991-92 and new immense pricing pressures from international competitors from Eastern Europe and South East Asia. Support from Major and Blair governments could have not been enough. Even if New Labour wanted to provide further assistance during 1997 - 2010 this would have violated the EU's Single Market regulations. UK manufacturing firms that survived focused more on quality rather than pricing.

However, the combination of the Great Recession that hit harder the UK, than the USA, France and Germany due to the reliance of the UK economy on financial services and the EU Referendum outcome would provide barriers to the UK's financial sector growth. These 
barriers would emerge due to the emergence on new macroeconomic conditions. The BE in its August inflation report, while forecasting the impact of the Referendum on the UK economy -acknowledging the difficulties with forecasting in such a fluid environment-, it took for granted that Brexit will lead to lower capital mobility (Bank of England, 2016). At present, EU governments are not allowed to apply capital restrictions, as this will distort efficiency in European capital markets most of which are located in London.- (footnote: Greece is the only exception to this rule due to ongoing mitigating circumstances). Brexit will inevitably lead to minor capital restrictions between the UK-EU27 capital transactions.

This does not mean that Brexit will render the UK a close economy, but it does mean some distortion in European financial markets, with its nature and magnitude almost impossible to anticipate, as it would depend on market's reaction to the negotiation process and the final Brexit agreement. The PM's Speech also pointed to a hard Brexit. The impact of the new conditions (hard Brexit plus lower degree of capital mobility between the UK-EU27) implies that capital efficiency would become very difficult to improve, and profits from the financial sector could suffer as a result. In addition, the potential loss of passporting rights likely to be downgraded to 'equivalence' for the UK banks and financial institutions to EU's Single market will render financial services to the rest of the EU more costly, once Brexit is materialised, with detrimental effects on the UK financial services (Cox 2017, Finch and Glover 2017). A decline in the financial sector's contribution to the UK's GDP is likely. This presents manufacturing as an obvious candidate based on which the UK economy could/needs to be restructured. 


\section{Why is manufacturing important in post-Brexit Britain?}

The contribution of manufacturing to the UK economic performance is vital, as it accounts almost for $10 \%$ of the country's GDP. Further and most important in the context of the UK-EU negotiations, it is the leading sector of the economy in terms of exports, accounting for 40$45 \%$ of all UK exports, $58 \%$ of which are sold to EU markets. Manufacturing also generates the majority, almost $70 \%$ of the UK's R\&D. Further, of all sectors of the UK economy is the most highly integrated with the rest of EU, in particular in supply chain production (CBI, 2016). It is therefore the sector that would be influenced the most by Brexit and the final Brexit agreement.

Overall, six sectors, (Construction, Education, Hospitality, Housing and real estates, Manufacturing, Professional and Business Services and Retail) generate almost 3 quarters of UK employment. However, a (hard) Brexit will have a different impact on each sector. For example, the obvious winner from the Referendum's Brexit outcome and the Pound's depreciation is Hospitality, Leisure and Tourism. The sector has already benefited from the Pound's depreciation and will most likely continue to do so by potential further depreciations once Brexit negotiations commence (BBC, 2017). The sector will only need a fast-Visa Process to become available to all tourists from EU-27 countries post Brexit. Other sectors, such as Education and Construction will be influenced negatively in the period leading to Brexit, but their non-tradable nature implies they do not contribute to the volumes of trade.

As it can be observed in Table-3, Construction from example, will be influenced from increases in the cost of labour, as it could suffer from shortages of less skilled labour. However, the sector accounts for only $£ 1.6$ and $£ 1.2 \mathrm{bn}$ worth of exports and imports respectively. Education and Real Estate, while they generate 5 million jobs, are non-tradable. Financial Services is the 
sector with the highest surpluses generating $f 54.9 \mathrm{bn}$. The loss of financial institutions passporting rights, could cause a significant reduction in these surpluses.

Table-3:

The UK economy and different sectors' contribution

\begin{tabular}{|l|c|c|c|c|c|}
\hline \multicolumn{1}{|c|}{ UK Economy } & $\begin{array}{c}\text { Employees } \\
\text { mn }\end{array}$ & $\begin{array}{c}\text { GVA } \\
\text { bn and \% }\end{array}$ & $\begin{array}{c}\text { Exports } \\
\text { bn }\end{array}$ & $\begin{array}{c}\text { Imports } \\
\text { bn }\end{array}$ & $\begin{array}{c}\text { Exports - } \\
\text { Imports }\end{array}$ \\
\hline Agriculture & 0.476 & 8.5 & 18 & 38.5 & -20.5 \\
Aviation & 0.961 & $52 / 3.4$ & 26 & & 26 \\
Chemicals and Plastics & 0.277 & $17.5 / 1.1$ & 26.9 & 27.8 & -0.9 \\
Construction & $\mathbf{2 . 2}$ & $102.3 / 6.2$ & $\mathbf{1 . 6}$ & $\mathbf{1 . 2}$ & 0.4 \\
Creative Industries & 1.9 & $87.4 / 5.3$ & 19.8 & 8.7 & 11.1 \\
Education & $\mathbf{2 . 9}$ & $98.1 / 5.9$ & - & - & - \\
Energy & 0.14 & $36.2 / 2.2$ & 76.7 tn & 154.8 tn & - \\
Financial Services & 1.1 & $119.2 / 7.2$ & 63.7 & 8.8 & $\mathbf{5 4 . 9}$ \\
Food \& Drink & 0.444 & $26 / 1.7$ & 18.2 & 38.5 & -20.3 \\
Hospitality, Leisure and Tourism & $\mathbf{3 . 1}$ & $121.1 / 7.1$ & 22 & 42.4 & -20.4 \\
Housing and Real Estate & $\mathbf{2 . 1}$ & $101.6 / 6.1$ & - & - & - \\
Life Sciences & 0.053 & $6.4 / 0.4$ & 20.7 & 19.6 & 1.1 \\
Manufacturing & $\mathbf{2 . 7}$ & $162.4 / 9.8$ & $\mathbf{2 2 8 . 9}$ & $\mathbf{3 1 3 . 3}$ & $\mathbf{- 8 4 . 4}$ \\
Professional and Business Services & $\mathbf{5 . 8}$ & $204.4 / 12.3$ & $\mathbf{7 0 . 5}$ & $\mathbf{4 0 . 4}$ & $\mathbf{3 0 . 1}$ \\
Retail & $\mathbf{5}$ & $182 / 10.9$ & $\mathbf{1 1 . 4}$ & $\mathbf{6 . 1}$ & 5.3 \\
Technology & 1.2 & $95.5 / 5.7$ & 20.8 & 29 & -8.2 \\
Transport, Distrib. and Logistics & 1.5 & $76.8 / 4.6$ & 24.1 & 21.7 & 2.4 \\
Utilities \& Environmental Services & 0.414 & $46.9 / 2.8$ & 6.4 & 4.7 & 1.7 \\
\hline TOTAL & $\mathbf{3 2 . 2 6 5}$ & \multicolumn{5}{|r|}{} \\
\hline
\end{tabular}

Table and calculations - author's own work, data from CBI. Sectors generating more than 2 million jobs in bold.

As it can be also observed, Manufacturing accounts for 2.7 million employees, $(8.3 \%$ of total UK employment). Despite therefore of its deficit of $£ 84.4 \mathrm{bn}$, manufacturing remains by far the most important exporting sector of the UK economy with $f 228.9 \mathrm{bn}$ worth of exports. To make the point clear, the second most export-orientated sector, that of Professional and Business Services, generates $£ 70.5 \mathrm{bn}$. And while Professional and Business Services together with Retail generate almost 11 million jobs, they generate only $£ 81.9 \mathrm{bn}$ worth of exports, less than a third than Manufacturing. 
As $40-45 \%$ of all UK exports are manufactured goods and services, and $58 \%$ of them are sold to EU markets, the sector exports to the EU from $£ 134.3$ to $151.1 \mathrm{bn}$. As a result, approximately a quarter of all UK exports are manufactured goods and services sold to EU markets. Therefore, Brexit, and in particular in the case of a 'hard' Brexit, that the PM alluded to in her Speech, the UK stands to lose a big proportion of a quarter of its exports on a permanent basis. The actual percentage is impossible to estimate, as it would depend on the final Brexit agreement. The point to be made, however, is that put simply, the UK government cannot 'ignore' manufacturing performance.

As a result, whether the adjustment of the UK's economy to the new economic environment prompted by the EU Referendum outcome and the impeding lengthy Brexit negotiations would be smooth, depends largely on the adjustment of the UK's manufacturing sector to the post-Brexit environment, and its responsiveness to the pound's depreciation in the interim period. Further, as already mentioned, the extension of the period that would lead to a balanced budget beyond 2020-21, confirmed by the Chancellor of the Exchequer in the preBudget report, 'creates' a new macroeconomic framework that places more emphasis on the adjustment of the economy rather than on fiscal consolidation, while acknowledging fiscal constraints. Or rather, renders fiscal consolidation contingent to a smooth post-Brexit adjustment. Crucial to this is the adjustment of the manufacturing sector to the Brexit conditions, given that almost half of the UK's exports are sold to EU markets.

As such, it is the author's view, that out of all sectors in the UK economy bar Hospitality, Leisure and Tourism, Manufacturing stands out as a potential Brexit winner, subject to appropriate policies been designed in the short-run and implemented in post-Brexit Britain. Certainly, the sector should receive most attention from all UK institutions. Manufacturing could emerge as a Brexit winner, as EU membership forbids the adoption of a 
national industrial policy, viewed as favouritism towards domestic firms and overall distorting competition within the EU context. This became a highly contentious issue when the UK authorities tried to rescue Tata Steel industry during 2014-16, but EU regulations provided an obstacle in doing so. Offering state support for example for a domestic firm, not only puts pressure on fiscal policy and public finances by committing tax payers money, but it also discriminates against other firms in the EU, and overall reduces European consumers' surplus. The same rationale applies to EU regulations not permitting the Italian government not been able to provide a rescue fund on Alitalia etc.

Brexit is also likely going to reinforce the trend away from sources of direct taxation. Given that in the EU context, striking the correct balance between direct and indirect taxation is constrained by economic policies pursued by other EU governments, Brexit will 'free' the hands of UK governments to 'pursue' a competitive tax policy (Wishart, 2017). Hence, the Chancellors' comments for potentially lowering corporation tax in the case of an unfavourable trade agreement with the EU-27. Accompanying a lower corporation tax, with lower business rates and tax incentives for the manufacturing sector will provide a complete set of tax policies to accommodate Brexit's British economy.

Further, the manufacturing sector's contribution to the narrowing of the UK's current account deficits would be vital. Given the unprecedented current account deficit exceeded 5\% of GDP in 2015 and 2016, revenue sources and the fiscal policy mix would also have to be adjusted, albeit ensuring a delayed return to a balanced budget (King 2016, Albanese et al. 2017). The Bank of England has estimated that the current account deficit will be halved from $5.2 \%$ to around 2.5-2.6\% by 2019, as a result of the Pound's depreciation (Bank of England, 2016). The estimate was based on a $9 \%$ depreciation in the value of the Pound. This optimistic forecast is based on the nature of the UK's current account deficits, which while unprecedented is not 
alarming. This nature points more to a decline in earnings on dividends and interest on foreign assets by UK residents during 2011-2015, in relation to payments to foreigners for their UK holdings over the same period (Giles and Fray, 2016). As companies that raise their profits abroad, in particular in \$dollars or Euros, are placed in a very strong position when they translate these in pounds (e.g. FTSE 100) the current account deficits are bound to be significantly reduced as early as 2017 .

Further, the impact of the depreciation will imply that domestic demand and exports will be even more important for future growth, as people in the UK will increase (proportionally) their purchase of domestically produced goods and services in relation to imported goods and services. As almost half exports are manufactured goods and services manufacturing will have to draw the UK government's attention. In addition, tax revenue sources and the contribution from direct and indirect taxation needs to reflect the new reality. Revenue sources have to be adjusted in the light of the return to a national industrial policy and significant volatility of the Pound-sterling/Euro and Pound-sterling/Dollar exchange rate.

As these policies were impossible to pursue in the EU context, but are an essential policy instrument of any post Brexit government, regardless of political background, new 'national' sources of finance have to become available. This requires a reshaping of the UK's macroeconomic policy based on government intervention, not previously permitted in the EU context. This new type of interventionist policy at a national level (be it Centre-left or Rightwing in nature), would need to be financed, by direct and indirect taxation. Above all, it would/should aim at reducing the productivity gap between the UK and other advanced economies including France and Germany. The productivity gap is reflected by the fact that the UK recovered its 2008 productivity rates per worker only in the second half of 2015/early 2016 (Giles and Fray, 2016). UK productivity also lags in relation to France and Germany by 
$20 \%$ and $30 \%$ respectively, as noted in the Chancellor's pre-Budget Report (Smith, 2017).

As a result, UK manufacturing firms should develop a preliminary assessment of the impact of:

- Potential break down in supply chains with production processes located in-part in other EU countries, from double-tariffs and quotas;

- Links between supply chains in manufacturing and financial services located to EU-27. This is essential as it could potentially have a detrimental impact on raising funds for the manufacturing sector and infrastructure investment. Such links need to be reviewed alongside the increased cost of servicing national debt and the Pound-toEuro volatility. The former would lead to higher cost of borrowing money for private sector firms, the latter would render contracts with European partners based on forward exchange rates difficult to agree. As result, convincing European partners to renew contracts, or commit to new ones would become a much more difficult process than it was in the past.

- Their responsiveness and impact from the Pound's depreciation and higher inflation.

- Adapt and incorporate digital technology in the production process - seek government subsidies to build digital capacity and enhance digital training skills.

A UK-national manufacturing policy could/should involve a two-tier system of regional and national financial assistance to firms and companies with a strong (or potentially strong) exporting capacity. The UK Manufacturing firms in collaboration with the UK authorities should:

1. Identify regional or national leaders (Hutton and Morales, 2017); 
2. Identify best practices from leaders and try to emulate to other cases;

3. Improve productivity in the production process by business investment programmes, adaptations and staff re-training (to be subsidised by the government);

4. Adopt the best-possible tax incentives (business rates, corporation tax, reinvestment tax breaks etc.);

5. Seek regional subsidies where possible, with an inclusive approach to Wales, Scotland and Northern Ireland;

6. Prepare a country case study, drawing on the existing arrangements with countries that could resemble the UK's status in relation to the EU, such as Norway, Switzerland, Turkey etc., and a detailed evaluation of their industrial policies. Emphasis would be placed on the rules, regulations and policies that can be adopted in the context of the UK economy.

7. Identify new markets for UK manufacturers, such as the USA-NAFTA, and seek to reduce barriers to trade with these as much as possible.

8. Manufacturing can be used as a tool by the UK government-authorities to reduce regional disparities and economic inequalities and performance across the UK.

9. Review education programmes in the light of the Brexit reality, e.g. adapt higher education programmes and unit syllabuses and enhance skill-training programmes in colleges and technical education;

10. Where possible, identify Brexit losers and ways that government policy could partly compensate them. For example, the UK automobile industry and its adjustment to a 'hard' Brexit. 
Events so far, and a series of impeding elections in EU countries in 2017, including France, the Netherlands, Germany and possibly Italy, point to a delayed hard-Brexit, most likely to occur at 2020, at the earliest. Therefore, the adjustment of the manufacturing sector in two periods, from 2017-Brexit, and then to the post-Brexit period is vital. Existing data on the volumes of trade between the UK and the EU should inform policies pre-Brexit that is within the existing EU framework subjected to high Pound-to-Euro exchange rate volatility. As such, the adjustment of the UK' manufacturing sector during 2017-Brexit will be dependent on: the pound's depreciation, the extent to which the depreciation would improve the UK's balance of payments deficit and the impact of the pound's depreciation on the rates of inflation.

Given that each $1 \%$ depreciation in the value of the pound, leads to an increase in exports by 0.2-0.3 percent, it is expected that the depreciation in the Pound by $16-18$ percent, will cause an increase in exports by $3.2-5.4$ percent. This increase in exports would alleviate the current account deficit but it would suffice to eliminate it. As a result, the manufacturing sector should prepare for a negotiating period featuring high uncertainty and a further pound depreciation. Coupled with appropriate post-Brexit policies, the manufacturing sector could play a key role in reshaping the UK's national accounts.

Ultimately, post-Brexit, the adjustment of the manufacturing sector would depend on whether the UK retains access to specific areas in the EU's Customs Union and industrial policies pursued by the UK authorities. These policies should not be subject to political developments in the UK. Therefore, the UK government could consider the establishment of an across party 'Institute of national-industrial policy' alongside existing government departments to facilitate the above aims.

As such, the main policy recommendation for the UK authorities is to focus on attaining the best possible trade agreement with the EU-27, and not viewing free trade areas with other 
countries/regions around the world, as a substitute for UK-EU trade relations. While agreeing on the general principles of such trade relations should be very welcome, the UK cannot legally bind itself to these, up until it has officially exited EU. This includes the UK-EU new trade deal. As such, new trade agreements should be secondary to the new UK - EU trade relations. Joining for example, the North American Free Trade Agreement (FAFTA), a free trade area that includes Mexico, Canada and the USA (Raphael, 2017) will be conducive to boosting UK exports to these three countries, but it cannot compensate trade losses from a 'bad' trade agreement with the EU, that would involve WTO tariffs and quotas. Given that as mentioned above, a quarter of all UK exports are manufactured goods and services are sold to EU markets, the geographical barrier between the UK and the three NAFTA members, is going to increase transport costs for UK exports. As the overwhelming majority of UK manufactured products are goods (e.g. cars), shipping these to the USA, Canada and Mexico is going to increase transport costs quite considerably in relation to shipping these from Hull to the Netherlands or Germany.

The UK could also seek to boost financial services exports to the USA, as in this market geographical distance no longer presents the barrier it used to. However, this would be subject to fierce competition from USA firms in the same sector. Further, bilateral agreements establishing free trade areas, are bound to encounter the exchange rate volatility between the Pound and the currencies under perspective, whereas trade with EU, essentially involves only the Pound-to-Euro exchange rate, as the rest of the EU currencies are in a fixed exchange rate regime with the Euro (e.g. Swedish and Danish Krone, Polish Zloty, Bulgarian Lev etc.). To conclude, while the UK negotiates its departure from the EU, it should develop an industrial strategy based on four main pillars:

i. Develop a national industrial policy to be implemented immediately after leaving 
the EU (if possible the day after!);

ii. Compensate the loss of trade with the EU-27, the new trade agreement with will brought about, by ensuring trade volumes with EU-27 do not decline considerably;

iii. In order to facilitate (ii), this would imply a considerable depreciation in the value of the pound, considerably lower than the current Pound-to-Euro rates, and put in place policies described above;

iv. Develop and join free trade areas/associations with other countries/regions, as a means of achieving (ii).

The Author would like to express his thanks to Prof Chris Pyke for help with data and referencing. 


\section{References}

1. Albanese, (2017) 'Pimco Bets Pound Plunge Is Far From Over as Brexit Clouds Gather' https://www.bloomberg.com/news/articles/2017-01-12/pimco-bets-pound-plunge-is-farfrom-over-as-brexit-clouds-gather downloaded 14/01/2017

2. Albanese, C., Krajewski, A. and Karamanis, V. (2017) 'What Charts Say About the Pound's Brexit Test'

https://www.bloomberg.com/news/articles/2017-01-17/pound-s-brexit-driven-acid-testintensifies-what-charts-show downloaded 17/01/2017

3. Bank of England (2016) 'Inflation Report'

http://www.bankofengland.co.uk/publications/Documents/inflationreport/2016/aug.pdf

4. BBC (2017) 'UK economy grows by $0.6 \%$ in fourth quarter'

http://www.bbc.co.uk/news/business-38755242 downloaded 27/01/2017

5. Burton, S. and Mogi, C. (2016) 'A Weaker Currency Is No Longer Economic Elixir It Once Was'

http://www.bloomberg.com/news/articles/2016-09-25/a-weaker-currency-is-no-longerthe-economic-elixir-it-once-was downloaded 26/09/2016

6. Cadman, E. (2016) 'Carney issues stark warning with package to ease Brexit downturn' FT.

http://www.ft.com/cms/s/0/0d729692-5a1a-11e6-9f7badea1b336d4.html\#axzz4GQotgOYv downloaded 05/08/2016

7. Confederation of British Industry (2016) 'Making Success of Brexit: A whole-Economy view of the UK-EU negotiations' December, 2016, CBI-Duncanprint.

8. Cox, J. (2017a) 'Optimism in financial services sector hits crisis era-low as Brexit concerns top worry list for banks Ninety per cent of banks questioned said that preparing for the impact of Brexit was their top challenge'

http://www.independent.co.uk/news/business/news/optimism-financial-services-sectorbanks-crisis-era-low-brexit-concerns-top-worry-list-for-banks-a7540936.html downloaded $23 / 01 / 2017$

9. Cox, J. (2017b) 'World Bank cuts UK growth forecast in first review since Brexit vote' http://www.independent.co.uk/news/business/news/world-bank-cuts-uk-growth-forecastbrexit-first-review-economy-prediction-a7521146.html

10. Editorial The Independent (2017) 'Let's not be naïve - Trump has the upper hand over Theresa May in trade negotiations The first is that America will put America first. The harsh message from the President does at least have the virtue of clarity' 22/01/2017 
http://www.independent.co.uk/voices/editorials/trump-has-the-upper-hand-over-theresamay-in-trade-negotiations-a7540306.html downloaded 22/01/2017

11. Finch, G. and Glover, J. (2017) 'Goodbye Passport, Hello Equivalence? Brexit Banks Lower Sights'

https://www.bloomberg.com/politics/articles/2017-01-13/goodbye-passport-helloequivalence-brexit-banks-lower-sights

12. Giles, C. and Fray, K. (2016) 'Eight charts showing state of UK economy before Bank of England rate decision', FT.

http://www.ft.com/cms/s/0/fd522642-5596-11e6-9664e0bdc13c3bef.html\#axzz4GQotgOYv downloaded on $07 / 11 / 16$.

13. Goodman, D. (2017) 'Pound Slides as UK Retail Sales Drop Most Since 2012'

https://www.bloomberg.com/news/articles/2017-01-20/pound-slides-as-u-k-retail-salesdrop-most-since-2012-chart downloaded 22/01/2017

14. Hamilton, S. and Swint, B. (2017) 'The U.K. economy is maintaining its stellar performance since the Brexit vote, but the reasons may be cause for concern.'

https://www.bloomberg.com/news/articles/2017-01-26/u-k-economy-dismisses-brexitthreat-as-growth-beats-forecasts download 26/01/2017

15. Hutton, R and Morales, Al. (2017) 'May Industrial Strategy Seeks to Pick Winning Areas for U.K.'

http://www.independent.co.uk/news/business/news/brexit-latest-news-uk-three-yearsslow-growth-rising-unemployment-reduced-incomes-ernst-young-ey-a7541016.html downloaded 23/01/2017

16. International Monetary Fund, (2017) 'IMF Data Access to Macroeconomic and Financial Data. Currency Composition of Official Foreign Exchange Reserves (COFER)'.

http://data.imf.org/?sk=E6A5F467-C14B-4AA8-9F6D-5A09EC4E62A4 downloaded $28 / 01 / 2017$

17. Khan, S. (2017) ‘EU Brexit negotiator Guy Verhofstadt says Theresa May can't 'cherry pick benefits of the European Union'

http://www.independent.co.uk/news/world/europe/chief-eu-brexit-negotiator-guyverhofstadt-theresa-may-cherry-pick-illusionspeech-benefits-european-a7531971.html downloaded 18/01/2017

18. King, S. (2016) 'The UK's balance of payments conundrum'

http://blogs.ft.com/the-exchange/2016/07/20/the-uks-balance-of-paymentsconundrum/?siteedition=intl\#recommended-h-504491470546859260

19. Meakin, L. (2017) 'Carney Sees Brexit Consumer Slowdown Ahead After Strength' 
https://www.bloomberg.com/news/articles/2017-01-16/carney-sees-brexit-consumerslowdown-coming-after-strong-2016 downloaded 17/01/2017

20. Merrick, R. (2017) 'EU wins first round of Brexit battle by 'forcing UK out of single market', former adviser warns Theresa May'

http://www.independent.co.uk/news/uk/politics/brexit-battle-eu-theresa-may-singlemarket-free-trade-deal-negotiations-sir-andrew-cahn-uk-economy-a7532791.html downloaded 18/01/2017

21. Morales, A. (2017) 'Merkel Seen Putting EU Values Ahead of Car Lobby in Brexit Talks' https://www.bloomberg.com/politics/articles/2017-01-18/merkel-seen-putting-eu-valuesahead-of-car-lobby-in-brexit-talks downloaded 18/01/2017

22. Mortiner, C. (2017) 'Germany's finance minister just said what Brexit deal he thinks Theresa May should go for Wolfgang Schäuble thinks Britain should go for a Switzerland-style deal

http://www.independent.co.uk/news/world/europe/brexit-latest-eu-germany-wolfgangschaeuble-finance-minister-hard-brexit-immigration-switzerland-a7540506.html downloaded 22/01/2017

23. Office for National Statistics, (2017a) 'UK consumer price inflation: Dec 2016' https://www.ons.gov.uk/economy/inflationandpriceindices/bulletins/consumerpriceinflatio n/latest

24. Office for National Statistics, (2017b) 'Gross domestic product, preliminary estimate: Oct to Dec 2016'

https://www.ons.gov.uk/economy/grossdomesticproductgdp/bulletins/grossdomesticprod uctpreliminaryestimate/octtodec2016 downloaded 29/01/2017

25. Ross-Thomas, E. (2017) 'Trump Offers Britain Quick Trade Accord as He Shuns Europe' https://www.bloomberg.com/news/articles/2017-01-15/trump-offers-u-k-quick-trade-dealas-may-plans-visit-times downloaded 16/01/2017

26. Sembhy, R. (2017) 'Brexit: UK faces three years of slow growth, rising unemployment and squeezed incomes, says Ernst and Young'

http://www.independent.co.uk/news/business/news/brexit-latest-news-uk-three-yearsslow-growth-rising-unemployment-reduced-incomes-ernst-young-ey-a7541016.html downloaded 23/01/2017

27. Smith, W. A. (2017) Theresa May needs to focus on changing the attitudes of British businesses as much as she does on Brexit

http://www.independent.co.uk/voices/brexit-theresa-may-speech-philip-hammondproductivity-andy-haldane-a7529721.html downloaded 17/01/2017 
28. Spezzati, S. (2017) 'Pound Rescued by May Faces Choppy Waters as Political Risks Loom'.

https://www.bloomberg.com/news/articles/2017-01-18/pound-rescued-by-may-faceschoppy-waters-as-political-risks-loom downloaded 18/01/2017

29. Syed, S. (2017) Brexit could cut wages by $30 \%$ over next two decades, says private equity boss Guy Hands

http://www.independent.co.uk/news/business/news/brexit-guy-hands-says-cut-wages-30percent-twenty-years-private-equity-a7540986.html downloaded 23/01/2017

30. Ward, J. (2017a) 'UK Retail-Sales Slump Hints at Cracks in Brexit Boom' Bloomberg, $20 / 01 / 2017$

31. Ward, J. (2017b) 'U.K. Economy's Brexit Success Still Leaves Companies Fretting' https://www.bloomberg.com/news/articles/2017-01-25/u-k-economy-s-brexit-success-stillleaves-companies-fretting downloaded 25/01/2017

32. Watts, J. (2017) 'Brexit: Theresa May promises to reveal 'negotiating priorities' in speech amid criticism over approach to EU withdrawal'

http://www.independent.co.uk/news/uk/politics/brexit-latest-theresa-may-speechnegotiating-priorities-article-50-a7530531.html downloaded 17/01/2017

33. Wishart, I. (2017) 'Seven Brexit Strategies Theresa May Could Use to Erode EU Unity' https://www.bloomberg.com/news/articles/2017-01-12/seven-brexit-strategies-theresamay-could-use-to-erode-eu-unity downloaded 12/01/2017

34. Withnall, A. (2017) UK could become 'tax haven' of Europe if it is shut out of single market after Brexit, Chancellor suggests

http://www.independent.co.uk/news/uk/politics/brexit-eu-chancellor-philip-hammondwelt-am-sonntag-uk-tax-haven-europe-a7527961.html downloaded 15/01/2017 